\title{
Artificial intelligence application for classification and selection of fish gelatin packaging film produced with incorporation of palm oil and plant essential oils
}

\author{
Natácia da Silva e Silva ${ }^{\mathrm{a}, \mathrm{b}}$, Fabricio de Souza Farias ${ }^{\mathrm{c}}$, Mauricio Madson dos Santos Freitas ${ }^{\mathrm{a}}$, \\ Enrique José Gregório Pino Hernández ${ }^{\mathrm{d}}$, Vanderson Vasconcelos Dantas ${ }^{\mathrm{b}}$, \\ Marcos Enê Chaves Oliveira ${ }^{\mathrm{e}}$, Maria Regina Sarkis Peixoto Joele ${ }^{\mathrm{f}}$, \\ Lúcia de Fátima Henriques Lourenço ${ }^{a}$
}

${ }^{a}$ LAPOA / FEA (Faculty of Food Engineering) Federal University of Pará, Rua Augusto Corrêa 01, Guamá, Belém, Pará, 66075-900, Brazil

${ }^{\mathrm{b}}$ Food Technology Department, Estadual University of Pará, UEPA, Cametá, Pará, Brazil

${ }^{\mathrm{c}}$ Faculty of Information Systems, Federal University of Pará (UFPA), Cametá, Pará, Brazil

${ }^{\mathrm{d}}$ CEB/Centre of Biological Engineering, University of Minho, Campus of Gualtar, Braga, 4710-057, Portugal

e Embrapa Eastern Amazon, Belém, Pará, Brazil

${ }^{\mathrm{f}}$ Federal Institute of Education, Science and Technology of Pará, Department of Food and Science Campus, Castanhal, Pará, Brazil

\section{A R T I C L E I N F O}

\section{Keywords:}

Waste

Artificial intelligence

KNN algorithm

Oil palm

Active packaging

\begin{abstract}
A B S T R A C T
The k-Nearest Neighbor (KNN) algorithm was used to classify and select biodegradable packaging produced from fish gelatine incorporated with palm oil and clove and oregano essential oils. All reinforced films are highly resistant to attraction, with an emphasis on a sample of clove essential oil with a value of 53.18 MPa. Also, the addition of palm oil and essential oils increases the elasticity and thickness of the packages. The packages have antioxidant and antimicrobial properties with an inhibition zone for $S$. aureus of 11.73 and $11.23 \mathrm{~mm}$ for the film with essential oil of oregano and film with palm oil, respectively. KNN proved to be efficient for the classification and selection of packaging. The results highlighted the packaging with clove essential oil as the best for presenting the highest values of antioxidant activity, tensile strength, and elongation. Palm oil is an interesting alternative for applications in biodegradable films due to its antimicrobial activity, antioxidant properties, abundance, and low cost. Packaging made of fish gelatin with the addition of vegetable oils is a promising alternative for food applications.
\end{abstract}

\section{Introduction}

The fish processing industries generate about $70 \%$ of waste about the final product. These residues can be used as raw material for the preparation of other products, contributing to the reduction of biological residues, which cause damage to the environment, in addition to reducing the economic losses of the fishing industries (Feltes et al., 2010; Karim \& Bhat, 2009).

Gelatin is a protein derived from the partial hydrolysis of collagen, which can be obtained from fish processing waste. It is used in the food and pharmaceutical industry, and recently its use has expanded to other applications, such as the preparation of biodegradable active packaging (Ahmad, Nirmal, \& Chuprom, 2015; Silva, Lourenço, \& Pena, 2017).

Active packaging not only protects but also interacts with the packaged product, providing desirable effects and extending its shelf life. Among the several types of active packaging, this study highlights the films that include oils that provide antimicrobial activity, modified atmosphere packaging, and oxygen and ethylene absorbers (Vermeiren, Devlieghere, Beest, Kruijf, \& Debevere, 2000; Silva, Lopes, Da Silva, \& Yoshida, 2016; Pirsa, Sani, \& Khodaeivandi, 2018; Pirouzifard, Yorghanlu, \& Pirsa, 2019; Chavoshizadeh, Pirsa, \& Mohtarami, 2020).

These oils have been studied because they have antioxidant and antimicrobial activity and contain compounds such as carvacrol, thymol, eugenol, and carotenoids. Several studies have indicated that these oils can be added to biodegradable films obtained from natural polymers such as chitosan and/or gelatin (Wu et al., 2014; Silva et al., 2016).

The preparation of biodegradable films of fish gelatin with the

E-mail address: natacia@uepa.br (N. da Silva e Silva). 
addition of essential oils has been widely studied (Gómez-Estaca, Bravo, Gómez-Guillén, Alemán, \& Montero, 2009; Tongnuanchan, Benjakul, \& Prodpran, 2014; Silva et al., 2016; Silva et al., 2017). However, no reports were found in the literature on the use of palm oil, which is considered more economically accessible compared to essential oils.

The addition of different oils gives specific chemical, physical, and mechanical properties to biodegradable films, changing their characteristics. Therefore, experimental analyses are necessary to establish more objectively which technological properties are more appropriate according to their applicability. However, most studies only describe the properties of films superficially and do not elucidate more precise results for their use, which is a limiting factor.

Gómez-Meire, Campos, Falqué, Díaz, and Fdez-Riverola (2014) and Chen et al. (2017) have indicated that this problem could be solved by using the k-Nearest Neighbor (KNN) algorithm, i.e., an artificial intelligence method that uses the Euclidean distance to group or classify similar items. The KNN is an algorithm based on the proximity of neighbors to assign the category of a new sample in a sample space and is suitable for small training sets (Alonso-Salces et al., 2004; Dasarathy, 1991). Thus, KNN method is suitable for the selection of packaging materials, as it mathematically analyzes the data, allowing the automatic definition of the best packaging properties. Thus, it reduces the number of laboratory analyzes necessary to define the best packaging among a set of tests carried out and, consequently, reducing the costs necessary to choose the best biodegradable film. (Dakhlaoui, Bargaoui, \& Bárdossy, 2012; Gómez-Meire et al., 2014).

Studies in the field of engineering and food science have shown that the KNN algorithm can be used to classify cider (Alonso-Salces et al., 2004), wines (Gómez-Meire et al., 2014), and vinegar (Chen et al., 2017), and is, therefore, a promising tool in the area of food research. However, until now, no study has tried to apply KNN to classify biodegradable active fish gelatin packaging derived from the by-products of fish processing with the addition of different oils.

This study aimed at classifying and selecting biodegradable active packaging produced with fish gelatin with the addition of palm oils and essential oils of cloves and oregano using an artificial intelligence tool, the KNN algorithm. To validate the results, a sensitivity analysis considering the results obtained from the $\mathrm{KNN}$ as a function of the laboratory analysis data was performed.

\section{Material and methods}

\subsection{Materials}

The fish skin (Cynoscion acoupa), used to obtain gelatin was purchased in the Ver-o-Peso market (Belém, Brazil). The hybrid palm oil BRS Manicoré was donated by the Brazilian Agricultural Research Corporation, a unit of Embrapa Amazônia Oriental (Belém, Brazil). Clove and oregano essential oils were purchased from Quinarí fragrances and cosmetics LTDA. Glycerol (Isofar, Glycerin PA with $99.5 \%$ purity) was used as a plasticizer, and pure gum Arabic powder (Dinâmica 97 Química Contemporânea Ltda, Brazil) was used as a surfactant.

\subsection{Extraction of gelatin from fish skin (Cynoscion acoupa) and preparation of biodegradable films}

The extraction of gelatin from the skin of acoupa weakfish and the preparation of biodegradable films followed the methodology described previously by Silva, Hernández, Araújo, Joele, and Lourenço (2018).

In the first stage, the fish skins were cut into $4 \mathrm{~cm} \times 4 \mathrm{~cm}$, washed in running water and immersed in a sodium chloride solution (Isofar, Brazil) $0.6 \mathrm{M} \mathrm{1:} 5$ (weight/volume) for $15 \mathrm{~min}$, shaking $85 \mathrm{rpm}$ at $25{ }^{\circ} \mathrm{C}$ in the Shaker incubator (Lucadema, Luca-223, Brasil). The second stage corresponded to the immersion of the fish skins in $0.3 \mathrm{M}$ sodium hydroxide solution, 1: 5 (weight/volume) (Vetec, Brazil) for $15 \mathrm{~min}$, with continuous agitation. Then the fish skins were washed with $0.02 \mathrm{M}$ acetic acid solution (Audaz, Brazil), 1: 5 (weight/volume) for $1 \mathrm{~h}$ with agitation. Then, the fish skins were washed under running water. The gelatin extraction was performed with distilled water in a water bath (Tecnal, Te-057, Brazil) for $12 \mathrm{~h}$ at $50{ }^{\circ} \mathrm{C}$, maintaining a 1: 5 ratio (weight/volume). After extraction, the filtered material was placed in stainless steel trays, frozen in an ultra-freezer (Coldlab, Cl, Brazil) and lyophilized at $-50^{\circ} \mathrm{C} / 36 \mathrm{~h}$ (Liotop - L101, Brazil). Finally, the gelatin obtained was packed in vacuum-sealed bags (Fastvac Wrapping Machine, F200, Brazil) and stored at $-26{ }^{\circ} \mathrm{C}$ in an ultra-freezer until the films were made.

For the production of the films, $2.30 \%$ gelatin, $13.18 \%(\mathrm{w} / \mathrm{w})$ plasticizers, $30 \%$ oil and $30 \%$ surfactant (gum Arabic) in relation to oil were used, which were mixed with distilled water $(\mathrm{p} / \mathrm{v})$ by suspension. The final solution was homogenized at $15,000 \mathrm{rpm}$ for $5 \mathrm{~min}$ in the Turratec homogenizer (Tecnal, TE-102, Brazil) to obtain the filmogenic solution. $120 \mathrm{~mL}$ of the filmogenic solution, were added in the form of silicone $(22 \mathrm{~cm}$ in diameter $\times 3 \mathrm{~cm}$ in height) and dried in a dryer (Quimis, Q315 M, Brazil) at $30{ }^{\circ} \mathrm{C}$ for $20 \mathrm{~h}$.

\subsection{Determination of the physical, mechanical, and barrier properties of biodegradable films}

The tensile strength (TS) and elongation (\%E) of the films were determined according to the ASTM D882-91 (ASTM, 1996) methodology using a texturometer (QTS, Brookfield) at a room temperature of 25 ${ }^{\circ} \mathrm{C}$. The initial separation of the claws and the probe speed were $50 \mathrm{~mm}$ and $1 \mathrm{~mm} . \mathrm{s}^{-1}$, respectively. The samples were cut to $10 \times 2.5 \mathrm{~cm}$ (length $\times$ width) (Limpan, Prodpran, Benjakul, \& Prasarpran, 2010). The tensile strength (TS) in MPa and elongation (\%E) were calculated using Eqs. (1) and (2), respectively.

$T S=\frac{F_{m}}{A}$

where TS: tensile strength (MPa); Fm: maximum force at the rupture of the film $(\mathrm{N})$; A: cross-sectional area of the film $\left(\mathrm{m}^{2}\right)$.

$E=\frac{E a}{d_{\text {initial }}} .100$

where: $\mathrm{E}$ : elongation (\%); $\mathrm{E}_{\mathrm{a}}$ : sample extension (mm); $\mathrm{d}_{\text {initial }}$ : initial distance of claw separation $(50 \mathrm{~mm})$.

The thickness of the films was measured using a digital micrometer with a resolution of $0.001 \mathrm{~mm}$ (Insize, model IP54). Eight random locations were selected in each film with $60 \mathrm{~mm}$ edge clearance.

Water vapor permeability (WVP) was determined using the modified ASTM D882-95 method described by Arfat, Benjakul, Prodpran, and Osako (2014). The film sample was sealed with silicone adhesive in a 4.5 $\times 7.0 \mathrm{~cm}$ glass container (diameter $\mathrm{x}$ height) containing $10 \mathrm{~g}$ of silica gel at $0 \% \mathrm{RH}$ and water vapor pressure $(\mathrm{Wp})$ at $30{ }^{\circ} \mathrm{C}$ equal to zero. The containers were placed in desiccators containing distilled water at $99 \%$ $\mathrm{RH} ; 4244.9$ water vapor pressure at $30^{\circ} \mathrm{C}$. They were weighed at $1 \mathrm{~h}$ intervals for $10 \mathrm{~h}$. WVP was calculated using Eq. (3).

$W V P=\frac{W, X}{A \cdot t \cdot \Delta P}$

where, WVP: water vapor permeability $\left(\mathrm{g} \cdot \mathrm{m}^{-1} \cdot \mathrm{s}^{-1} \cdot \mathrm{Pa}^{-1}\right.$.); W: weight gain due to the desiccant (g); X: film thickness (m); A: surface area of the exposed film $\left(\mathrm{m}^{2}\right)$; $\mathrm{t}$ : incubation time (seconds); $\Delta \mathrm{P}$ : partial pressure difference $(\mathrm{Wp})$. The experiments were carried out in triplicate.

To evaluate the solubility, the films were cut into $2 \mathrm{~cm}$ diameter discs and placed in an oven at $105^{\circ} \mathrm{C}$ for $24 \mathrm{~h}$ and were weighed. The dry films were then immersed in containers with $50 \mathrm{~mL}$ of water. This system was agitated in a refrigerated Shaker Incubator (Lucadema, Luca-223 model) with a speed of $150 \mathrm{rpm}$ for $24 \mathrm{~h}$ at $25^{\circ} \mathrm{C}$. After this period, the samples were filtered, and the retained material was dried $\left(105^{\circ} \mathrm{C}\right.$ for $\left.24 \mathrm{~h}\right)$ to 
determine the material not dissolved in water (Gontard, Duchez, Cuq, \& Guilbert, 1994).

The water content was provided following the recommendations of the AOAC (1997), and water activity (Aw) was measured using AQUALAB 4TE (Decagon Devices, USA).

The color of the films was determined using a MINOLTA CR 310 colorimeter, obtaining parameters of $L^{*}$ (luminosity), a* (intensity of red), $b^{*}$ (intensity of yellow), $C^{*}$ (chroma value), $H^{*}$ (hue angle), and the total color difference $\left(\Delta \mathrm{E}^{*}\right)$ calculated using Eq. (4).

$\Delta E *=\sqrt{(\Delta L)^{2}+(\Delta a *)^{2}+(\Delta b *)^{2}}$

\subsection{Antioxidant and antimicrobial activity of biodegradable films}

The antioxidant activity was determined using UV-vis absorption spectrophotometry using the ABTS radical (2,2'-azino-bis (3-ethylbenzothiazolin) 6-sulfonic acid), according to the methodology described previously by Re et al. (1999). The procedure adopted to determine the antimicrobial activity of the films was the zone of inhibition using the disc-diffusion agar method, according to Gómez-Estaca et al. (2009). The films were cut into $1.5 \mathrm{~cm}$ diameter discs and placed in plates containing Mueller-Hinton agar (MHA) medium, previously inoculated with Staphylococcus aureus and Escherichia coli. These microorganisms were chosen because they are frequently related to Foodborne Diseases. The inoculant with approximately $10^{8} \mathrm{~mL}^{-1}$ of CFU was previously standardized using the McFarland Scale. The plates were incubated at $37^{\circ} \mathrm{C}$ for $24 \mathrm{~h}$, and the diameters of the growth inhibition zones around the discs were measured using a millimeter caliper. All tests were conducted in triplicate.

\subsection{Data analysis}

The results of the analysis of tensile strength, elongation, thickness, water vapor permeability, solubility, moisture, water activity, and antioxidant and antimicrobial activity, underwent an analysis of variance (ANOVA) and Tukey's test ( $\mathrm{p} \leq 0.05)$ using Statistic 7.0 (Statsoft, 2004).

An artificial intelligence analysis was used to classify and select the best conditions for the biodegradable film using the KNN algorithm, as described below:

Obtaining data: In this step, results were obtained in triplicate from the analysis of water activity, tensile strength, elongation, thickness, water vapor permeability, solubility, moisture, antioxidant, and antimicrobial activity of the films, an obtaining a data set of 24 samples.

Definition of the characteristics of an ideal biodegradable film: To define the ideal characteristics, the values obtained from each laboratory analysis were compared considering two possible states, i.e., "the higher the value obtained in the analysis, the better" or ", the lower the value obtained in the analysis, the better." The choice between higher and lower values was made based on the literature (Tongnuanchan et al., 2014; Silva et al., 2016) and according to expert analyses. Subsequently, the analyses used to calculate the weighted average of the KNN algorithm were classified in order of priority. From the definition of the ideal biodegradable film, the following ideal characteristics were obtained with the respective order of priority: $1^{\text {a }}$ - higher value of antioxidant activity; $2^{\mathrm{a}}$ - higher value of antimicrobial activity; $3^{\mathrm{a}}$ higher value of tensile strength; $4^{\mathrm{a}}$ - higher value of elongation; $5^{\mathrm{a}}$ - lower value of water vapor permeability; $6^{\mathrm{a}}$ - lower value of solubility; $7^{\mathrm{a}}$ lower value of thickness; $8^{\text {a }}$ - lower value of water activity; $9^{a}$ - lower value of moisture.

Definition of the ideal biodegradable film: At this stage, an algorithm selected the combination that represents the ideal film from the 24 records in the database considering the list of priorities of the analyses and characteristics of an ideal film based on the literature.

Classification and selection of the best film: The Euclidean distance of each record was calculated using $\mathrm{KNN}$, obtaining the ranking of the films more similar to the ideal, classifying and defining the most appropriate film to be used as biodegradable packaging. The shorter the Euclidean distance, the more similar the film will be to the ideal one.

Therefore, considering a data set previously classified as $X=\left\{x_{1}, x_{2}\right.$, $\left.\ldots, x_{n}\right\}$ and a new observation defined by $Y=\left\{y_{1}, y_{2}, \ldots, y_{n}\right\}$, the Euclidean distance was obtained using Eq. (5). All the tests were conducted with Matlab.

$D(X, Y)=\sqrt{p_{1}\left(x_{1}-y_{1}\right)^{2}+p_{2}\left(x_{2}-y_{2}\right)^{2}+\ldots+p_{n}\left(x_{n}-y_{n}\right)^{2}}$

where $p_{i}$ is an element of the dataset, $P=\left\{p_{1}, p_{2}, \ldots, p_{n}\right\}$, where $n$ is the vector size that can be used to apply weighting based on the order of priority of the elements.

Two analyses were considered to obtain the best film. The first was composed of weighted weights considering the order of priority of the elements. In this case, the linear function $p_{i}=-0.1125 p r_{\text {elem }}+1.1125$ was defined, where $p r_{\text {elem }}$ represents the element priority order varying from one (antioxidant activity) to nine (moisture). The second, in turn, was composed of equal weights and a constant function composed by the given $P$ dataset: $p_{i}=\{1 \mid 0<j<10\}$, where $j$ is the element of the list of priorities, varying from one (antioxidant activity) to nine (moisture).

\section{Results and discussion}

\subsection{Determination of the properties of biodegradable films}

The results of the analysis of the technological properties are shown in Table 1. The control film had a higher value of tensile strength, followed by the films with clove essential oil, palm oil, and oregano essential oil, with a significant difference. These values may be related to

Table 1

Results of the physical, mechanical, and color characteristics of biodegradable films.

\begin{tabular}{|c|c|c|c|c|}
\hline Analyses & Control & Palm oil & Clove oil & Oregano oil \\
\hline TS (MPa) & $87.01 \pm 3.58^{\mathrm{a}}$ & $38.12 \pm 1.25^{c}$ & $53.18 \pm 0.28^{\mathrm{b}}$ & $27.82 \pm 0.22^{\mathrm{d}}$ \\
\hline Elongation (\%) & $115.04 \pm 0.29^{d}$ & $126.73 \pm 0.11^{\mathrm{c}}$ & $127.20 \pm 0.2^{\mathrm{bc}}$ & $127.77 \pm 0.07^{\mathrm{a}}$ \\
\hline Thickness (mm) & $0.04 \pm 0.00^{\mathrm{d}}$ & $0.07 \pm 0.00^{\mathrm{b}}$ & $0.06 \pm 0.00^{c}$ & $0.09 \pm 0.00^{\mathrm{a}}$ \\
\hline WVP & $2.13 \pm 0.24^{\mathrm{d}}$ & $3.31 \pm 0.35^{\mathrm{c}}$ & $5.04 \pm 0.47^{\mathrm{b}}$ & $7.33 \pm 0.12^{\mathrm{a}}$ \\
\hline Solubility (\%) & $19.01 \pm 0.52^{\mathrm{a}}$ & $11.84 \pm 0.09^{\mathrm{b}}$ & $11.20 \pm 0.22^{\mathrm{b}}$ & $19.08 \pm 0.56^{\mathrm{a}}$ \\
\hline Humidity (\%) & $6.27 \pm 0.30^{\mathrm{d}}$ & $11.41 \pm 0.76^{\mathrm{c}}$ & $12.05 \pm 0.51^{\mathrm{b}}$ & $12.90 \pm 0.48^{\mathrm{a}}$ \\
\hline Aw & $0.42 \pm 0.00^{c}$ & $0.45 \pm 0.04^{c}$ & $0.56 \pm 0.00^{\mathrm{b}}$ & $0.60 \pm 0.00^{\mathrm{a}}$ \\
\hline$L^{*}$ & $88.58 \pm 0.13^{\mathrm{a}}$ & $79.50 \pm 0.43^{c}$ & $87.16 \pm 0.09^{\mathrm{b}}$ & $86.38 \pm 1.21^{\mathrm{b}}$ \\
\hline$a^{*}$ & $-3.77 \pm 0.06^{\mathrm{a}}$ & $-0.01 \pm 0.55^{\mathrm{b}}$ & $-3.30 \pm 0.02^{\mathrm{a}}$ & $-3.71 \pm 0.08^{\mathrm{a}}$ \\
\hline$b^{*}$ & $7.88 \pm 0.29^{\mathrm{d}}$ & $87.50 \pm 2.10^{\mathrm{a}}$ & $13.73 \pm 0.41^{\mathrm{b}}$ & $8.49 \pm 0.00^{\mathrm{cd}}$ \\
\hline$C^{*}$ & $8.67 \pm 0.27^{\mathrm{d}}$ & $88.84 \pm 0.21^{\mathrm{a}}$ & $14.12 \pm 0.41^{\mathrm{b}}$ & $9.45 \pm 0.24^{\mathrm{cd}}$ \\
\hline $\mathrm{H}$ & $117.72 \pm 0.76^{a}$ & $89.75 \pm 0.35^{\mathrm{d}}$ & $103.54 \pm 0.29^{c}$ & $114.10 \pm 0.14^{\mathrm{b}}$ \\
\hline$\Delta \mathrm{E}$ & - & $95,88 \pm 0.37^{\mathrm{a}}$ & $6.03 \pm 0.30^{\mathrm{b}}$ & $2.31 \pm 0.02^{c}$ \\
\hline
\end{tabular}

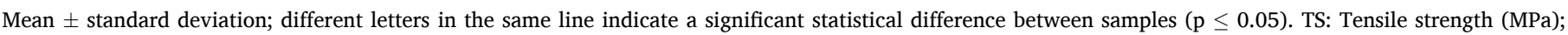
Elongation (\%); Water vapor permeability: WVP $\left(\mathrm{x} 10^{-11} \mathrm{~g} \cdot \mathrm{m}^{-1} \cdot \mathrm{S}^{-1} \cdot \mathrm{Pa}^{-1}\right)$. 
the type of oil because their composition interacts differently with proteins in the formation of films (Bakkali, Averbeck, Averbeck, \& Idaomar, 2008; Hoque, Benjakul, \& Prodpran, 2011). Tongnuanchan et al. (2014) and Silva et al. (2016) also observed a decrease in tensile strength with the addition of oils in fish gelatin and chitosan films, respectively.

The addition of palm oil and essential oils provided greater elasticity (\%E) to the films compared to the control, indicating the plasticizing property of the evaluated oils (Table 1). According to Wang et al. (2011) and Limpisophon, Tanaka, and Osako (2010), the addition of oils in films causes an increase in elongation, because the hydrophobic substances of the oils prevent the protein chains from interacting, and, consequently, the films produced are less rigid and more flexible.

The thickness of the films containing palm oil and essential oils was greater than that of the control $(p \leq 0.05)$, due to the increase in the number of solids that penetrate the internal structure of the film, preventing the protein molecules from interacting. The film with oregano essential oil had the greatest thickness, followed by the films with palm oil and clove essential oil. According to Tongnuanchan et al. (2014), this variation in thickness is related to different surface stresses and the size of the oil droplets, as they have different compositions.

The control film had the lowest water vapor permeability (WVP) compared to the films with the addition of oils ( $\mathrm{p} \leq 0.05)$. The increase of WVP in films with oils is related to the use of gum Arabic as a surfactant due to its hydrophilic characteristic (Román-Guerrero et al., 2009). It was also observed that the highest values of thickness are related to the increase in WVP (Table 1), which agrees with the results of studies conducted by Mchugh and Krochta (1994); Rivero, García, and Pinotti (2009), Abugoch, Tapia, Villamán, Yazdani-Pedram, and Díaz-Dosque (2011), and Pereda, Ponce, Marcovich, Ruseckaite, and Martucci (2011). Wu et al. (2014) and Silva et al. (2016) also found that the addition of different oils to films did not cause a decrease in WVP.

The palm oil film had the lowest WVP compared to the films with clove or oregano essential oil. This may be related to the fact that palm oil is made up of a mixture of saturated, monounsaturated and polyunsaturated fatty acids, interacting homogeneously with proteins, leaving protein-protein bonds weaker, decreasing hydrophilic bonds. This finding is important because essential oils have a higher market value compared to palm oil. In addition, palm oil is one of the most commercialized used oils worldwide and has a high nutritional value due to the presence of tocopherols, which are physiologically active as vitamin E, and palmitic, oleic, and linoleic fatty acids (Edem, 2002; Sundram, Sambanthamurthi, \& Tan, 2003).

Palm and clove films had the lowest values of solubility, $11.84 \%$, and $11.20 \%$, respectively. The solubility of the films in this study was lower compared to those produced by Wu et al. (2014), who found values from $30.16 \%-32.81 \%$ in gelatin and chitosan films with oregano essential oil. Low solubility films are indicated for packaging food, while highly soluble films can be used as a coating by immersion in food products (Ahmad et al., 2015).

The control film had lower moisture, water activity, WVP, and thickness, which can be attributed to the absence of gum Arabic, which is a hydrophilic component. These characteristics resulted in higher TS of the control film when compared to the films with oils due to the greater intermolecular interaction of its protein chains.

The palm oil film was yellow and duller in color, with a lower $L$ value and higher $\mathrm{b}^{*}$ compared to the other biodegradable films. The chroma value $\left(\mathrm{C}^{*}\right)$ indicated a greater color intensity and a tone angle close to $90^{\circ}$, confirming the yellow color of the film with palm oil. The most significant color difference $(\Delta \mathrm{E})$ for the palm film is associated with the presence of high concentrations of carotenoids, mainly $\beta$-carotene (Baharin, Latip, Che Man, \& Rahman, 2001; Ribeiro, Barreto, \& Coelho, 2011). The addition of different oils has a direct impact on the color of the films produced and can be an important parameter to consumer acceptance when used as packaging.
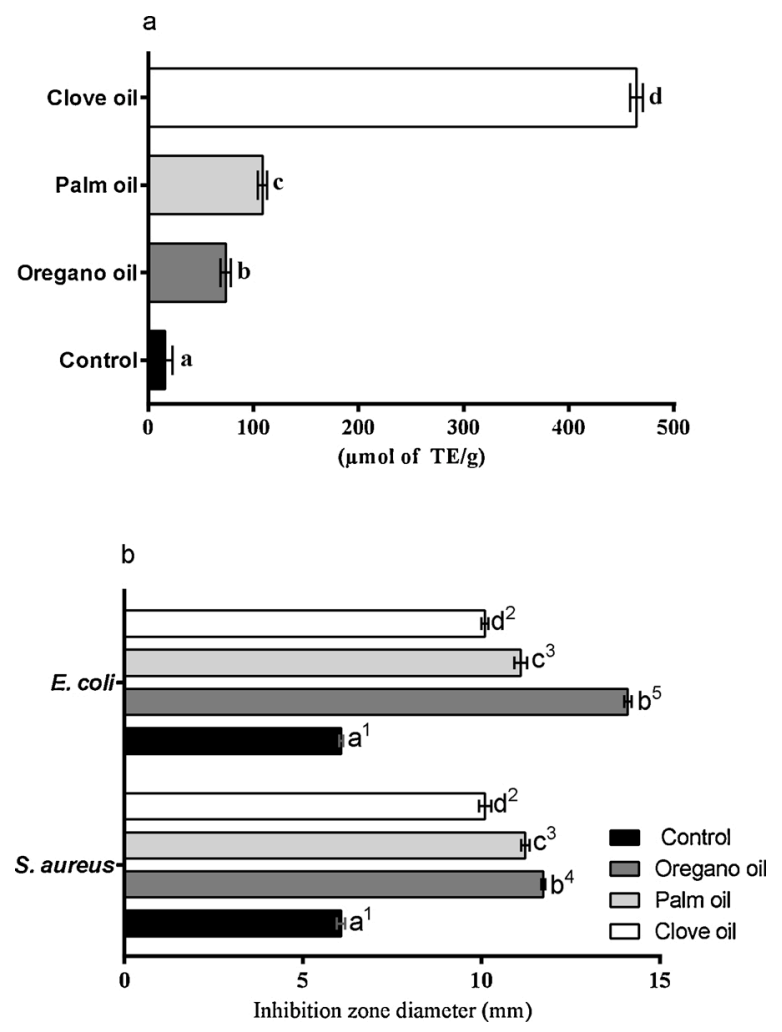

Fig. 1. Antioxidant (a) and antimicrobial (b) activity of biodegradable films with different oils. Different letters in the graph indicate significant statistical differences between samples ( $\mathrm{p} \leq 0.05)$. $a, b$, $c$, and $d$ indicate significant differences between the different treatments for each microorganism. 1, 2, 3, 4, and 5 indicate significant differences between the different microorganisms for each of the treatments.

\subsection{Antioxidant and antimicrobial activity of biodegradable films}

The control film showed less antioxidant activity, and the best results were found in the films with clove essential oil, followed by those with palm and oregano essential oils (Fig. 1a). The antioxidant activity of the clove and oregano essential oils was reported in a study conducted by Dimitrios (2006) and Gulçin, Elmastas, and Aboul-Enein (2012). According to Jirovetz, Buchbauer, Stoyanova, Krastanov, and Schmidt (2006) and Gulçin et al. (2012), the antioxidant activity of clove essesntial oil is due to the presence of compounds such as eugenol, beta-caryophyllene, and eugenyl acetate. Palm oil, in turn, shows high antioxidant activity because it contains high concentrations of phenolic compounds, such as carvacrol, terpene, and p-Cimene (Dimitrios, 2006), flavonoids, carotenoids, tocopherols, and palmitic, oleic, and linoleic fatty acids (Edem, 2002; Sundram et al., 2003).

The films incorporated with palm oil and essential oils showed greater antimicrobial activity for the microorganisms tested compared to the control, with a significant difference $(\mathrm{p}<0.05)$ (Fig. 1b). According to Minervini et al. (2003) and Di Bernardini et al. (2011), the antimicrobial activity of fish gelatin is due to the presence of oligopeptides and lateral chain amino acids. Gómez-Estaca et al. (2009), in turn, found no antimicrobial activity in the biodegradable films of fish and chitosan gelatin that they prepared. However, according to Jeon, Kamil, and Shahidi (2002), López-Caballero, Gómez-Guillén, Pérez-Mateos, and Montero (2005), and Fernández-Saiz, Soler, Lagaron, and Ocio (2010), the results of the antimicrobial activity of this raw material may vary depending on the experimental procedures used.

The oregano essential oil film showed the highest antimicrobial activity with an inhibition zone of $14.1 \mathrm{~mm}$ for $E$. coli and $11.73 \mathrm{~mm}$ for $S$. aureus, results close to those found for the palm oil film in relation to 
the inhibition zone for $S$. aureus which was of $11.23 \mathrm{~mm}$. However, for E. coli, the inhibition zone was less with value of $11.1 \mathrm{~mm}$. According to Lambert, Skandamis, Coote, and Nychas (2001) and Oussalah, Caillet, Salmiéri, Saucier, and Lacroix (2004), the antimicrobial activity of oregano essential oil is due to the presence of phenolic compounds, such as carvacrol, thymol, and eugenol, which have significant antimicrobial effects, especially for E. coli, as is observed in the present study.

The antimicrobial activity of palm oil, in turn, is due to the presence of tocopherols, which are physiologically active as vitamin E, and the palmitic, oleic, and linoleic fatty acids (Edem, 2002; Sundram et al., 2003). The results found for palm oil are relevant and can be compared with those found for oregano essential oil, which is reported in the literature for its high antimicrobial activity. Moreover, palm oil has lower commercial value, being one of the most consumed oils worldwide, and is easy to extract and has high yields (Junior et al., 2017). Palm oil may be an effective alternative for the preparation of active packaging with antimicrobial and antioxidant activity for the control of food pathogens, maintaining the nutritional composition of the food.

The clove oil film was effective in the control of the two microorganisms tested, with no significant difference, and inhibition zone values of $10.1 \mathrm{~mm}$ for both $E$. coli and $S$. aureus. The antimicrobial activity of clove oil can be attributed to its content of monoterpenes that degrade the cytoplasmic membrane of bacteria (Zhang et al., 2008).

As observed in the statistical analysis of variance (ANOVA) and Tukey's test, it was not possible to establish which biodegradable packaging is more viable for technological application, and, therefore, the KNN classification algorithm was applied in the results obtained to define the ideal film.

\subsection{Classification and selection of biodegradable films using the KNN algorithm}

Table 2 shows the results of the assumption of the ideal film obtained through artificial intelligence using the $\mathrm{KNN}$ algorithm, based on a description of the literature and a list of priorities.

Results indicate that the ideal film should show high values of antioxidant activity, close to those found in the clove oil film. The ideal film should have an antimicrobial activity of $14.20 \mathrm{~mm}$, which is higher than the results found for the films in this study. The high values of tensile strength and elongation obtained indicate that the films are strong and elastic, which are important properties for packaging. The ideal WVP value is $1,75 \times 10^{-11} \mathrm{~g} \cdot \mathrm{m}^{-1}$. $\mathrm{S}^{-1}$. Pa, which is lower than those found in the films analyzed in the present study.

The solubility of palm and clove essential oils films (Table 1 ) is close to the ideal value. The ideal film should be thin and have a low propensity for microorganism development, based on the results of thickness, water activity, and moisture that were obtained. Although the oil films had higher moisture than non-oil films, their water activity was within the maximum limit of 0.6 . In Fig. 2, shows the classification and selection of biodegradable films using the KNN algorithm.

Two experiments were conducted to assess data variability. The first considered the importance of each element (order of priority and characteristic of the analyses) represented by the "weighted ranking

Table 2

Assumption of ideal fish gelatin film with oils.

\begin{tabular}{ll}
\hline Analyses & Results \\
\hline Antioxidant activity & $480.79(\mu \mathrm{mol} \mathrm{of} \mathrm{TE} / \mathrm{g})$ \\
Antimicrobial activity & $14.20(\mathrm{~mm})$ \\
Tensile strength & $93.02(\mathrm{MPa})$ \\
Elongation & $127.86(\%)$ \\
Water vapor permeability & $1.75 \times 10^{-11} \mathrm{~g} \cdot \mathrm{m}^{-1} \cdot \mathrm{S}^{-1} \cdot \mathrm{Pa}$ \\
Solubility & $10.89(\%)$ \\
Thickness & $0.04(\mathrm{~mm})$ \\
Water activity & 0.38 \\
Humidity & $5.01(\%)$ \\
\hline
\end{tabular}

weight" and the second considered that all items had the same weight, represented by the "equal ranking weight." The clove essential oil film had the shortest Euclidean distance (13-18), which had weighted and equal weight values of 39.06 and 45.68, respectively (Fig. 2). Therefore, the clove essential oil film was classified as the most appropriate film among all films assessed because it had the value closest to the ideal film, defined by the KNN algorithm, followed by the palm oil, oregano essential oils, and control films.

Considering the weighted and equal weights, the results of the laboratory analyses varied in scale, but not in order. Therefore, only Euclidean distance varied, with the maintenance of the order of films and their respective positions in the ranking. This finding supports the effectiveness of the algorithm to classify the best biodegradable film from a database.

The clove essential oil gelatin film showed the highest values of antioxidant activity (Fig. 1), which contributed to its indication as the first in the ranking defined by the KNN algorithm. This is a positive characteristic in the development of active packaging and allows clove essential oil gelatin film to be used to minimize or prevent lipid oxidation in food products, maintaining their quality and prolonging their commercial life. Moreover, the clove essential oil film had the highest values of tensile strength and elongation (Table 1) compared to the palm and oregano essential oils films. These are important properties for packaging, making them similar to synthetic packaging, which is highly resistant and flexible.

Palm oil film was ranked second in the ranking, showing good antioxidant and antimicrobial properties, and having low water vapor permeability and moisture. According to Galdeano, Mali, Grossmann, Ymashita, and García (2009), a low WVP is indicated for biodegradable films, because it prevents the transfer of humidity between food and the external environment, consequently increasing the commercial life of the packaged product. Therefore, the film defined as the ideal by the KNN algorithm should show good antioxidant and antimicrobial properties, and have low water vapor permeability.

Supporting the role of the algorithm, Gómez-Meire et al. (2014), analyzing the authenticity of white wine varieties in northwestern Spain using software, observed that classification methods such as Support Vector Machines (SVM), Random Forests (RF), MultiLayer Perceptron (MLP), KNN, and Naïve Bayes (NB) obtained similar results when analyzing the esters present in wines, and that the KNN algorithm was the best classifier for compounds, such as acids. In another article, Chen et al. (2017), when analyzing Chinese vinegar, reported that KNN is a good classification technique for volatile compounds, which was also observed in the present study. The algorithm could classify the biodegradable films, indicating the best film with the technological properties required to produce packaging with antioxidant and antimicrobial activities. It is noteworthy that no studies have reported the use of this algorithm to classify biodegradable packaging.

Fig. 3 illustrates the sensitivity analysis of the variation in the Euclidean distance of weighted and equal weights as a function of antioxidant and antimicrobial activity. The sensitivity analysis showed low values of Euclidean distance for films with high values of antioxidant activity (Fig. 3a), indicating that they produce the best films. However, low values of antioxidant activity increase Euclidean distance, thus reducing the viability and quality of film production. The best films are obtained when the antimicrobial activity (Fig. 3b) is around $10 \mathrm{~mm}$ and results above or below this value result in changes in film quality. Fig. 4 shows the sensitivity analysis of the variation in the Euclidean distance in relation to weighted and equal weights of solubility, thickness, water activity, moisture, tensile strength, elongation, and water vapor permeability.

In Fig. 4, it can be observed that the best films are those with the lowest solubility (Fig. 4a) and thickness (Fig. 4b) because higher values increase the Euclidean distance for both weighted weight, which considers the order of priority of the samples, and equal weight. The best results of water activity (Fig. 4c) are around 0.5 , and the best results of 


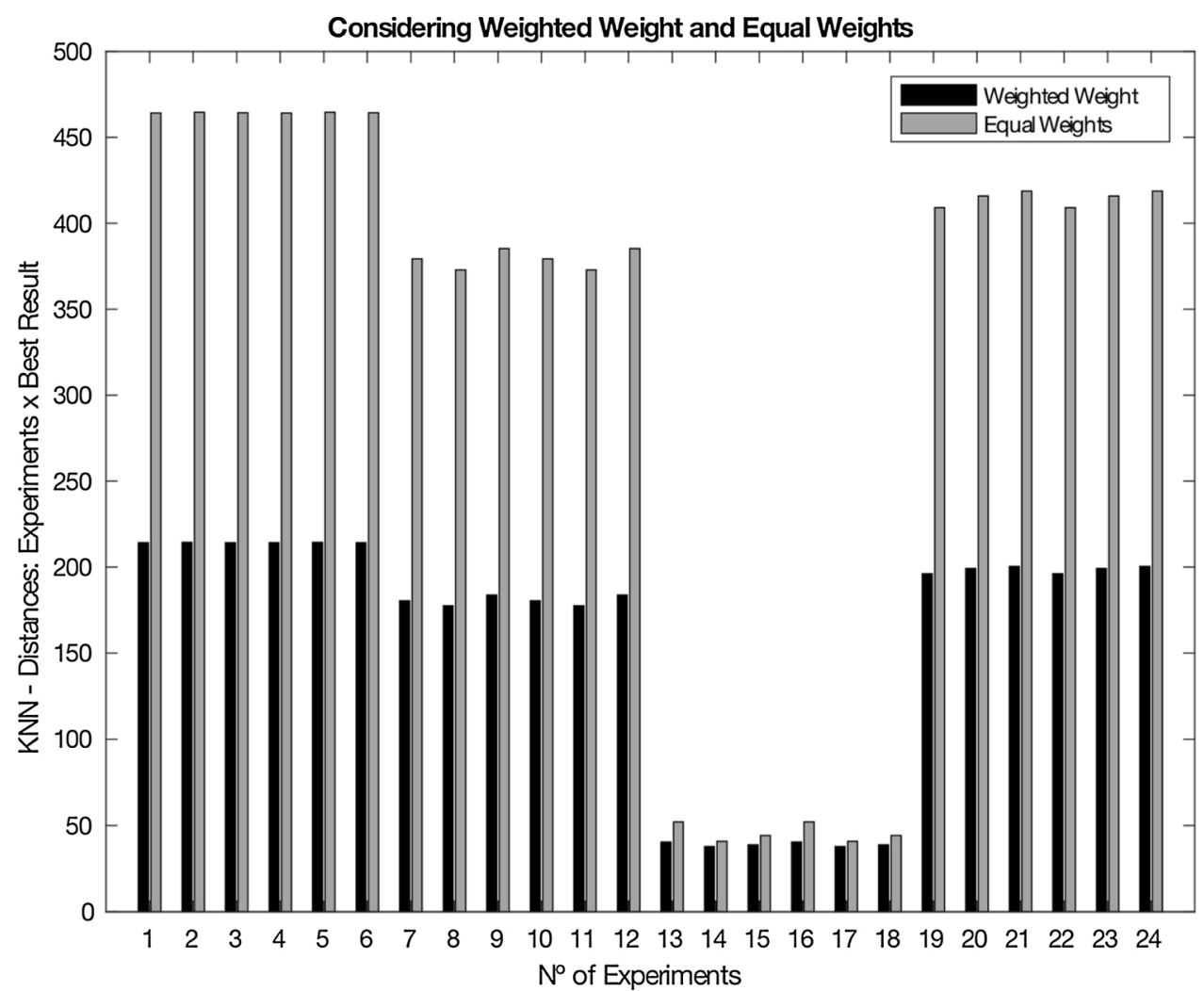

Fig. 2. Results of Weighted Weight Ranking, Equal Weight Ranking, and Ranking Position of the different biodegradable films. Experiments, control film (1 to 6), and films with oils: palm oil (7 to 12), clove oil (13 to 18), and oregano oil (19 to 24).
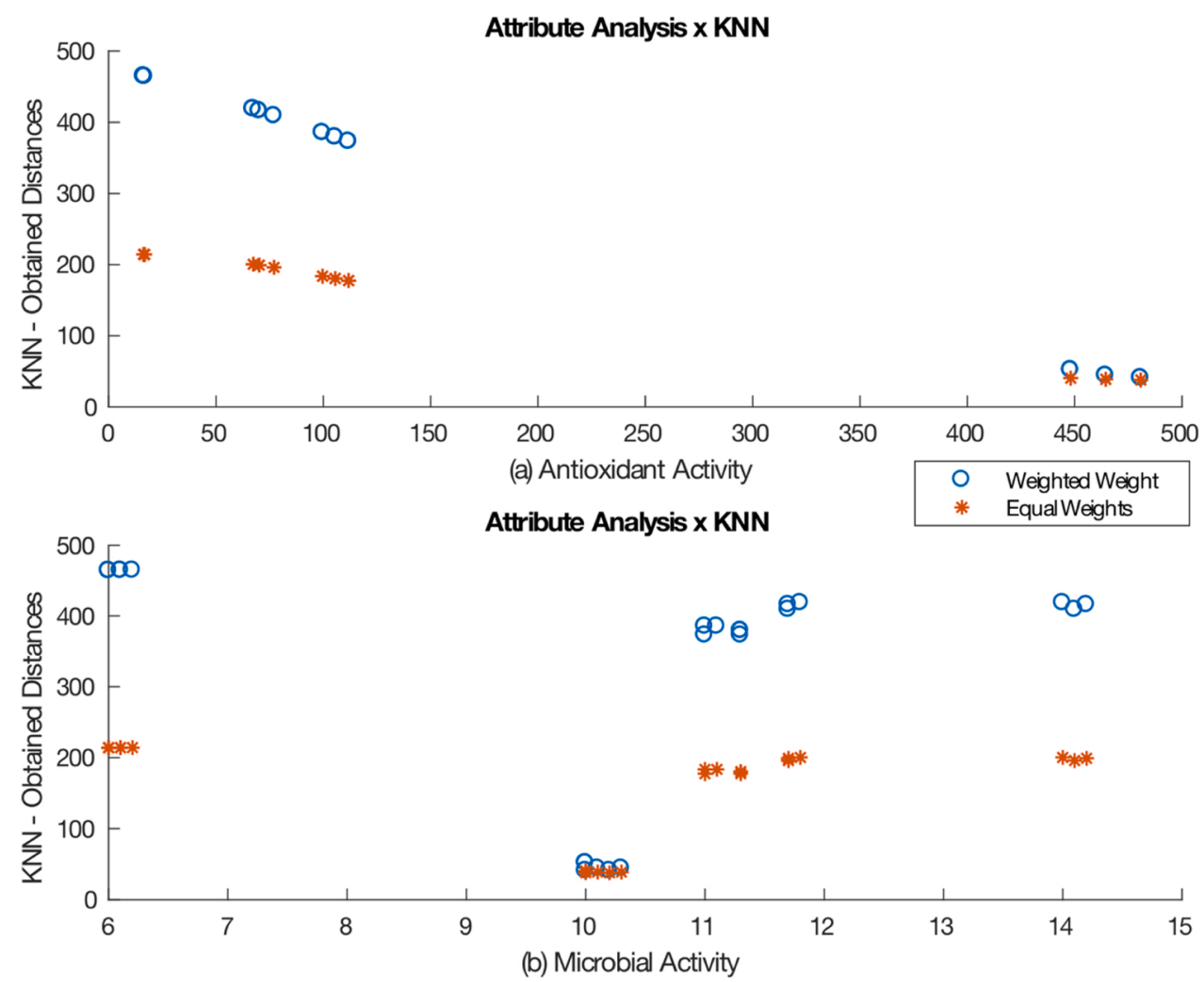

Fig. 3. Euclidean distance obtained using KNN for the weighted and equal weight for antioxidant activity (a) and antimicrobial activity (b). 


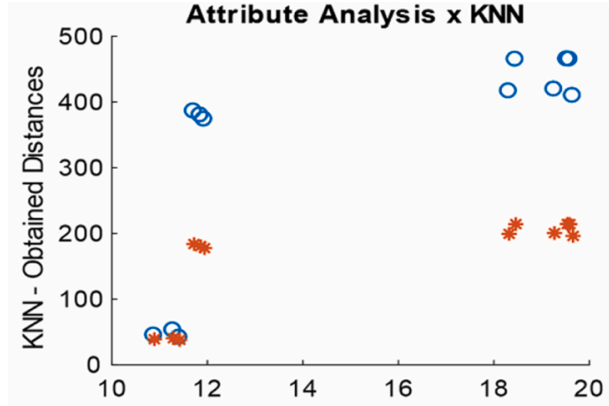

(a) Solubility

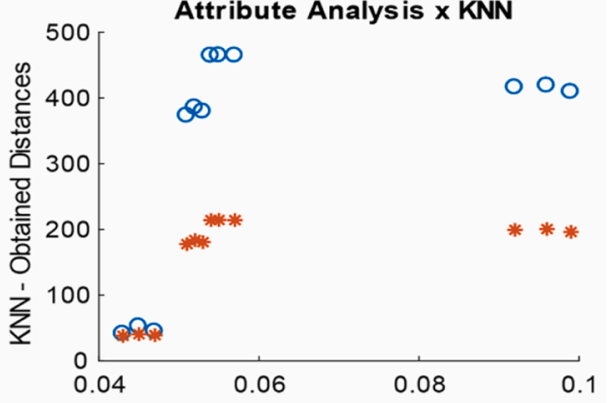

(b) Thickness

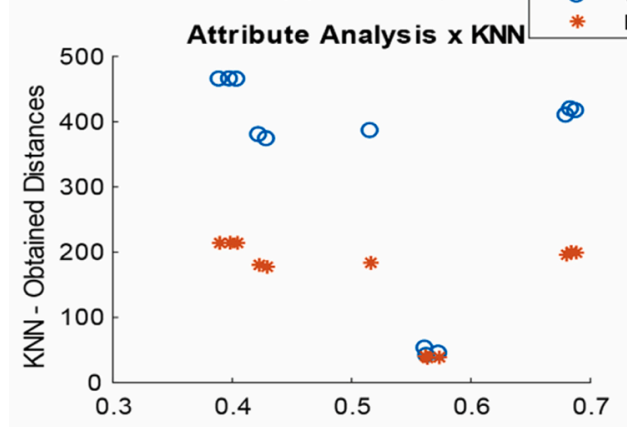

(c) Water Activity
Weighted Weight
Equal Weights Attribute Analys is $x$ KNN

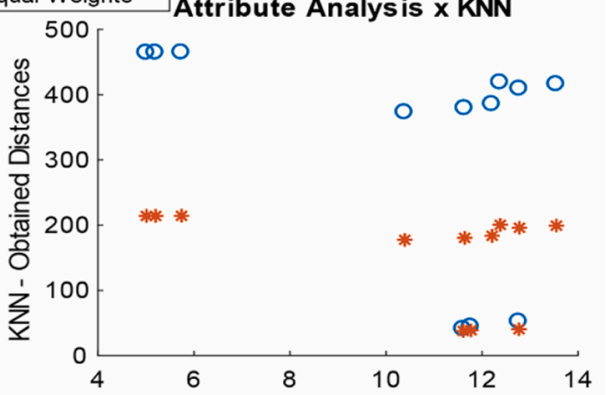

(d) Moisture
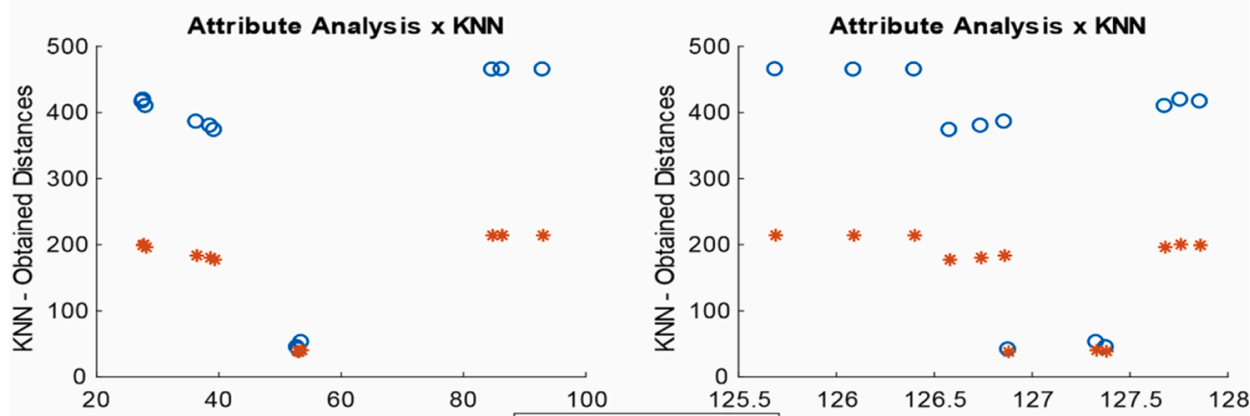

(e) Tensile Strength

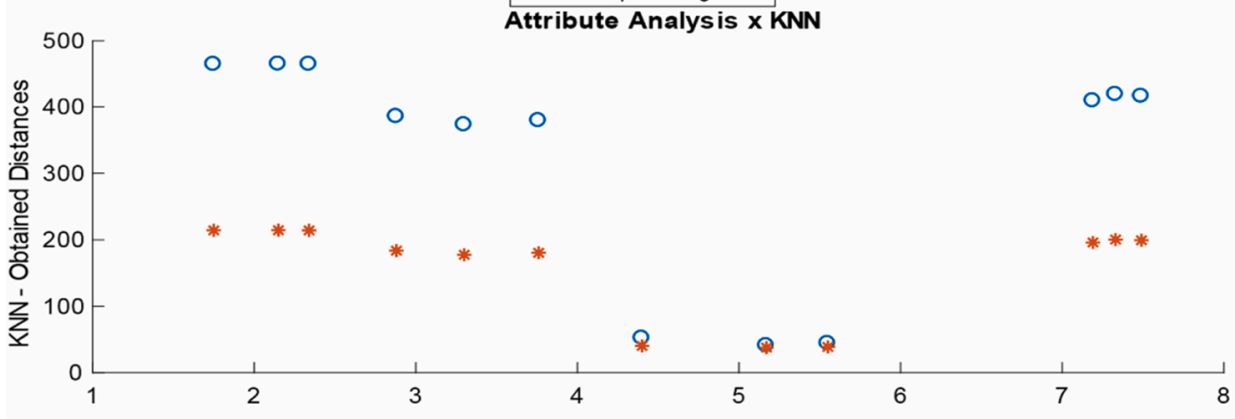

(g) Permeability to Water Vapor

Fig. 4. Euclidean distance obtained using KNN for weighted and equal weight for solubility (a), thickness (b), water activity (c), humidity (d), tensile strength (e), elongation (f), and water vapor permeability ( $g$ ).

moisture (Fig. 4d) range from 12 to 13. For values above or below those stated, there is an increase in the Euclidean distance for weighted and equal weights, leading to a decrease in the quality of the films produced.

The best films are those with a tensile strength (Fig. 4e) of about 50 $\mathrm{MPa}$, an elongation (Fig. 4f) of about $127 \%$, and a water vapor permeability (Fig. $4 \mathrm{~g}$ ) of about $4,5 \times 10^{-11} \mathrm{~g} \cdot \mathrm{m}^{-1}$. $\mathrm{S}^{-1}$, because they have the lowest values of Euclidean distance and consequently the best quality film. However, there is a decrease in quality with an increase in the Euclidean distance, considering the weighted and equal weights, when increasing or decreasing the values.

\section{Conclusions}

The addition of oils had an impact on the properties of biodegradable packaging. The films presented adequate technological properties to be used as packaging, making it an option for the use of waste produced by the fishing industries. The KNN algorithm proved to be a reliable method for classifying and selecting biodegradable packaging. The film produced with fish gelatin and clove essential oil is the most promising based on studies with KNN because it presented the highest values of antioxidant activity, tensile strength, and elongation. Although clove 
essential oil films are more promising, as previously presented, palm oil films are an interesting alternative, mainly due to their abundance and low cost. Thus, we believe that more in-depth studies should be conducted, in order to explore the potential of palm oil and its desirable qualities for the production of biodegradable films.

\section{Declaration of Competing Interest}

The authors report no declarations of interest.

\section{Acknowledgement}

The authors thank the Coordination for the Improvement of Higher Education Personnel (CAPES) for the financial support.

\section{Appendix A. Supplementary data}

Supplementary material related to this article can be found, in the online version, at doi:https://doi.org/10.1016/j.fpsl.2020.100611.

\section{References}

Abugoch, L. E., Tapia, C., Villamán, M. C., Yazdani-Pedram, M., \& Díaz-Dosque, M. (2011). Characterization of quinoa protein- chitosan blend edible films. Food Hydrocolloids, 25, 879-886.

Ahmad, M., Nirmal, N. P., \& Chuprom, J. (2015). Blend film based on fish gelatine/ curdlan for packaging applications: Spectral, microstructural and thermal characteristics. RSC Advances, 5, 99044-99057.

Alonso-Salces, R. M., Guyot, S., Herrero, C., Berrueta, L. A., Drilleau, J. F., Gallo, B., et al (2004). Chemometric characterisation of Basque and French ciders according to their polyphenolic profiles. Analytical Biochemistry, 379, 464-475.

AOAC. (1997). Association of official analytical chemists: Official methods of analysis (16th ed.).

Arfat, Y. A., Benjakul, S., Prodpran, T., \& Osako, K. (2014). Development and characterisation of blend films based on fish protein isolate and fish skin gelatin. Food Hydrocolloids, 39, 58-67.

ASTM. (1996). Standard test methods for tensile properties of thin plastic sheeting. Annual book of ASTM standards. ASTM D882-91. Philadelphia: ASTM.

Baharin, B. S., Latip, R. A., Che Man, Y. B., \& Rahman, A. (2001). The effect of carotene extraction system on crude palm oil quality, carotene composition, and carotene stability during storage. Journal of the American Oil Chemists' Society, 78, 851-855.

Bakkali, F., Averbeck, S., Averbeck, D., \& Idaomar, M. (2008). Biological effects of essential oils - A review. Food and Chemical Toxicology, 46, 446-475.

Chavoshizadeh, S., Pirsa, S., \& Mohtarami, F. (2020). Conducting/smart color film based on wheat gluten/chlorophyll/polypyrrole nanocomposite. Food Packaging and Shelf Life, 24, Article 100501.

Chen, Y., Bail, Y., Xu, N., Zhou, M., Li, D., Wang, C., et al. (2017). Classification of Chinese vinegars using optimized artificial neural networks by genetic algorithm and other discriminant techniques. Food Analytical Methods, 10, 2646-2656.

Dakhlaoui, H., Bargaoui, Z., \& Bárdossy, A. (2012). Toward a more efficient Calibration Schema for HBV rainfall-runoff model. Journal of Hydrology, 444-445, 161-179.

Dasarathy, B. V. (1991). Nearest neighbor (NN) norms: NN pattern classification techniques. Los Alamitos, CA, USA: IEEE Computer Society Press.

Di Bernardini, R., Harnedy, P., Bolton, D., Kerry, J., O'Neill, E., \& Mullen, A. M. (2011) Antioxidant and antimicrobial peptidic hydrolysates from muscle protein sources and by-products. Food Chemistry, 124, 1296-1307.

Dimitrios, B. (2006). Sources of natural phenolic antioxidants. Trends in Food Science \& Technology, 17, 505-512.

Edem, D. O. (2002). Palm oil: Biochemical, physiological, nutritional, hematological and toxicological aspects: A review. Plant Foods for Human Nutrition, 57, 319-341.

Feltes, M. M. C., Correia, J. F. G., Beirão, L. H., Block, J. M., Ninow, J. L., \& Spiller, V. R. (2010). Alternativas para a agregação de valor aos resíduos da industrialização de peixe. Revista Brasileira de Engenharia Agrícola e Ambiental, 14, 669-677.

Fernández-Saiz, P., Soler, C., Lagaron, J. M., \& Ocio, M. J. (2010). Effects of chitosan films on the growth of Listeria monocytogenes, Staphylococcus aureus and Salmonella spp. in laboratory media and in fish soup. International Journal of Food Microbiology, 137, 287-294.

Galdeano, M. C., Mali, S., Grossmann, M. V. E., Ymashita, F., \& García, M. A. (2009). Effects of plasticizers on the properties of oat starch films. Materials Science and Engineering, 29, 532-538.
Gómez-Estaca, J., Bravo, L., Gómez-Guillén, M. C., Alemán, A., \& Montero, P. (2009). Antioxidant properties of tuna-skin and bovine-hide gelatin films induced by the addition of oregano and rosemary extracts. Food Chemistry, 112, 18-25.

Gómez-Meire, S., Campos, C., Falqué, E., Díaz, F., \& Fdez-Riverola, F. (2014). Assuring the authenticity of northwest Spain white wine varieties using machine learning techniques. Food Research International, 60, 230-240.

Gontard, N., Duchez, C., Cuq, J., \& Guilbert, S. (1994). Edible composite films of wheat gluten and lipids - water-vapor permeability and other physical-properties. International Journal of Food Science \& Technology, 29, 39-50.

Gulçin, I., Elmastas, M., \& Aboul-Enein, H. Y. (2012). Antioxidant activity of clove oil - A powerful antioxidant source. Arabian Journal of Chemistry, 5, 489-499.

Hoque, M. S., Benjakul, S., \& Prodpran, T. (2011). Effects of partial hydrolysis and plasticizer content on the properties of film from cuttlefish (Sepia pharaonis) skin gelatin. Food Hydrocolloids, 25, 82-90.

Jeon, Y.-J., Kamil, J. Y. V. A., \& Shahidi, F. (2002). Chitosan as an edible invisible film for quality preservation of herring and Atlantic cod. Journal of Agricultural and Food Chemistry, 20, 5167-5178.

Jirovetz, L., Buchbauer, G., Stoyanova, A. I. S., Krastanov, A., \& Schmidt, E. (2006). Chemical composition and antioxidant properties of clove leaf essential oil. Journal of Agricultural and Food Chemistry, 54, 6303-6307.

Junior, R. A. G., Pina, A. J. A., Gurgel, F. L., Franzini, V. I., Carvalho, E. A., Veiga, A. S., et al. (2017). Sistema de produção de mudas em híbridos interespecíficos entre caiaué e dendê. Cîencia Florestal, 27, 169-179.

Karim, A. A., \& Bhat, R. (2009). Fish gelatin: Properties, challenges, and prospects as an alternative to mammalian gelatins. Food Hydrocolloids, 23, 563-576.

Lambert, R. J. W., Skandamis, P. N., Coote, P., \& Nychas, G.-J. E. (2001). A study of the minimum inhibitory concentration and mode of action of oregano essential oil, thymol and carvacrol. Journal of Applied Microbiology, 91, 453-462.

Limpan, N., Prodpran, T., Benjakul, S., \& Prasarpran, S. (2010). Properties of biodegradable blend films based on fish myofibrillar protein and polyvinyl alcohol as influenced by blend composition and pH level. Journal of Food Engineering, 100, 85-92.

Limpisophon, K., Tanaka, M., \& Osako, K. (2010). Characterisation of gelatin-fatty acid emulsion films based on blue shark (Prionace glauca) skin gelatin. Food Chemistry, 122, 1095-1101.

López-Caballero, M. E., Gómez-Guillén, M. C., Pérez-Mateos, M., \& Montero, P. A. (2005). Chitosan-gelatin blend as a coating for fish patties. Food Hydrocolloids, 19, 303-311.

Mchugh, T. H., \& Krochta, J. M. (1994). Sorbitol vs glycerolplasticized whey protein edible films: Integrated oxygen permeability and tensile property evaluation. Journal of Agricultural and Food Chemistry, 42, 841-845.

Minervini, F., Algaron, F., Rizzello, C. G., Fox, P. F., Monnet, V., \& Gobbetti, M. (2003). Angiotensin I-converting-enzyme-inhibitory and antibacterial peptides from Lactobacillus helveticus PR4 proteinase-hydrolysec casein of milk from six species. Applied and Environmental Microbiology, 69, 5297-5305.

Oussalah, M., Caillet, S., Salmiéri, S., Saucier, L., \& Lacroix, M. (2004). Antimicrobial and antioxidant effects of milk protein-based film containing essential oils for the preservation of whole beef muscle. Journal of Agricultural and Food Chemistry, 52, 5598-5605.

Pereda, M., Ponce, A. G., Marcovich, N. E., Ruseckaite, R. A., \& Martucci, J. F. (2011). Chitosan-gelatin composites and bi-layer films with potential antimicrobial activity. Food Hydrocolloids, 25, 1372-1381.

Pirouzifard, M., Yorghanlu, R. A., \& Pirsa, S. (2019). Production of active film based on potato starch containing Zedo gum and essential oil of Salvia officinalis and study of physical, mechanical, and antioxidant properties. Journal of Thermoplastic Composite Materials, 33(7), 915-937.

Pirsa, S., Sani, I. K., \& Khodaeivandi. (2018). Design and fabrication of starch-nano clay composite films loaded with methyl orange and bromocresol green for determination of spoilage in milk package. Polymers for Advanced Technologies, 29(11), 2750-2758.

Re, R., Pellegrini, N., Proteggente, A., Pannala, A., Yang, M., \& Rice-Evans, C. (1999). Antioxidant activity applying an improved ABTS radical cation decolorization assay. Free Radical Biology \& Medicine, 26, 1231-1237.

Ribeiro, B. D., Barreto, D. W., \& Coelho, M. A. Z. (2011). Technological aspects of $\beta$ carotene production. Food and Bioprocess Technology, 4, 693-701.

Rivero, S., García, M. A., \& Pinotti, A. (2009). Composite and bi-layer films based on gelatin and chitosan. Journal of Food Engineering, 90, 531-539.

Román-Guerrero, A., Orozco-Villafuerte, J., Pérez-Orozco, J. P., Cruz-Sosaa, F., JiménezAlvaradoa, R., \& Vernon-Carterd, E. J. (2009). Application and evaluation of mesquite gum and its fractions as interfacial film formers and emulsifiers of orange peel-oil. Food Hydrocolloids, 23, 708-713.

Silva, M., Lopes, P. S., Da Silva, C. F., \& Yoshida, C. M. P. (2016). Active packaging material based on buriti oil - Mauritia flexuosa L.f. (Arecaceae) incorporated into chitosan films. Journal of Applied Polymer Science, 133, 1-9.

Silva, E. V., Lourenço, L. F. H., \& Pena, R. S. (2017). Optimization and characterization of gelatin from kumakuma (Brachyplatystoma filamentosum) skin. CYTA - Journal of Food, 15, 1947-6337. 
Silva, N. S., Hernández, E. J. G., Araújo, C. S., Joele, M. R. S. P., \& Lourenço, L. F. H. (2018). Development and optimization of biodegradable fish gelatin composite film added with buriti oil. CYTA - Journal of Food, 16, 340-349.

Statsoft. (2004). Statistics for Windows, version 7.0.

Sundram, K., Sambanthamurthi, R., \& Tan, Y.-A. I. (2003). Palm fruit chemistry and nutrition. The Journal of Clinical Nutrition, 12, 355-362.

Tongnuanchan, P., Benjakul, S., \& Prodpran, T. (2014). Comparative studies on properties and antioxidative activity of fish skin gelatin films incorporated with essential oils from various sources. International Aquatic Research, 6, 1-12.

Vermeiren, L., Devlieghere, F., Beest, M. V., Kruijf, N., \& Debevere, J. (2000). Development in the active packaging of foods. Trends in Food Science \& Technology, $10,77-86$.
Wang, L. N., Liu, F., Jiang, Y. F., Chai, Z., Li, P. L., Cheng, Y. Q., et al. (2011). Synergistic antimicrobial activities of natural essential oils with chitosan films. Journal of Agricultural and Food Chemistry, 59, 12411-12419.

Wu, J., Ge, S., Liu, H., Wang, S., Chen, S., Wang, J., et al. (2014). Properties and antimicrobial activity of silver carp (Hypophthalmichthys molitrix) skin gelatinchitosan films incorporated with oregano essential oil for fish preservation. Food Packaging and Shelf Life, 2, 7-16.

Zhang, H., Shen, Y., Bao, Y., He, Y., Feng, F., \& Zheng, X. (2008). Characterization and synergistic antimicrobial activities of food-grade dilution-stable microemulsions against Bacillus subtilis. Food Research International, 41, 495-499. 